and similar tasks. In Exeter details of dialysis schedules are planned by computer for individual patients, and this is claimed to reduce morbidity. Like the Charing Cross programs, these would all be immediately welcome in almost any unit, since their relevance to day-to-day work is plain.

Another development which computing permits and was lucidly described by Professor Adrian Smith, of Nottingham, is the regular use of detailed, complex statistical analyses. A computer performs complicated calculations in microseconds, allowing the use of statistical methods not yet in general use in medicine. At Nottingham the department of mathematical statistics is' now developing statistical programs with the renal unit. One of these programs has been applied to sequential plasma creatinine results and has been shown to detect important changes of function in transplanted kidneys in a standardised way and at an earlier time than achieved by an experienced clinician. These programs have considerable promise for use both as early-warning systems and for evaluating the effect of changes in treatment. On-line statistical analyses should soon be able to be performed by a computer already on line to accept results direct from the laboratory.

The immediate problem is integrating these contributions, which have been developed using several different computer languages on different computers. As much compatibility as practicable should also be sought by computer planners with the centralised systems run by UK Transplantand the European Dialysis and Transplantation Association to calculate national and European statistics; and they should also take account of the need to include potential new developments. In realistic terms, however, many of those attending left the meeting with one thought: how to get the money to buy a computer for their unit now-and not wait for the long-heralded economic recovery.

\section{Metal allergy: A false alarm?}

Metal implants in surgery became routine only after the major problems of electrolytic corrosion had been recognised and overcome. ${ }^{1}$ Though the cobalt-chrome alloys, stainless steels, and other metals since used are largely inert in the body, they do all ionise slightly and small amounts can be found in the adjacent tissues. ${ }^{2-4}$ Furthermore, whenever there is friction between metal surfaces or between metal and bone relatively large quantities of the metal are shed, and traces appear in the blood, urine, and hair. ${ }^{5}$ Dermatologists have long recognised allergic responses from contact between the skin and nickel, cobalt, and chromium-all important constituents of many surgical implants.

Patch testing of the skin has shown cell-mediated delayed sensitivity to any one of these metals in up to $6.9 \%$ of the population, ${ }^{6}$ though the figure varies considerably from district to district. When patients with metal implants are tested in this way they show an increased prevalence of metal sensitivity. ${ }^{78}$ Conversion from a negative to a positive response to patch testing may occur after a hip arthroplasty. ${ }^{9}$ The recent use of more sensitive laboratory tests for sensitivity such as the lymphocyte-transformation technique ${ }^{1011}$ or the measurement of the release of leucocyte inhibition factor ${ }^{12}$ has confirmed these observations and shown that an even higher proportion of the population is metal sensitive. In one study, for example, 18 out of 32 patients with isolated bone screws were metal sensitive. ${ }^{12}$ The highest incidence of all-over two out of three-has been found in patients with loose but uninfected metal-to-metal hip prostheses, ${ }^{7} 810111314$ though one survey flatly contradicted these findings. ${ }^{15}$ These are the patients receiving the largest dose of the potential allergen from their implants.

Does this induced hypersensitivity matter? Indeed, does the implantation of a metal allergen into an already sensitive patient have the unwelcome clinical effects that might be expected ? There have been only a handful of well-documented circumstantial accounts of generalised allergic responses in patients with orthopaedic implants, ${ }^{12}{ }^{16-20}$ in whom symptoms were relieved by removing the metal, only to return on its reapplication to the skin. This evidence has been criticised, ${ }^{21}$ but even if accepted at face value the number of such reports is exceedingly small in comparison with the many thousands of implants in use. In clinical practice allergic dermatitis is so protean in its causes and capricious in its response to treatment that no firm conclusion is possible on the risks of a generalised reaction to implanted metal.

Might allergy be a possible explanation ${ }^{13}$ of local inflammation around an implant and of its loosening in bone? The evidence in favour is the well-established correlation of metal sensitivity with loose joint prostheses, but the alternative explanation is that the loosening causes the allergy. On the allergy theory, a local allergic vasculitis causes bone death; against that is the fact that the metal in a joint prosthesis will usually be insulated from the bone by a layer of non-allergenic acrylic cement. In one case endarteritis attributed to cobalt sensitivity was a feature in the tissues surrounding the necrotic and fibrosed muscle next to a chrome-cobalt plate on an ulna, yet a similar plate on the adjacent radius showed no "rejection" at all. ${ }^{22}$ Low-grade inflammation is not uncommon around bone plates and has usually been attributed to either the irritant effects of corrosion products or to infection, even if cultures prove sterile. In another case a patient with confirmed skin sensitivity to nickel needed a prosthetic heart valve. ${ }^{23}$ Testing with subcutaneous samples of the nickel-containing steel produced no general or local response, and none followed the later insertion of the valve.

The evidence for local allergic response is inconclusive, and unless it becomes stronger the verdict must be "Not guilty." Many patients who have received metal implants will acquire metal sensitivity, but in very few will the sensitivity cause clinically important complications. The chances of an adverse reaction are too remote to justify special alarm or precautions.

1 Venable CS, Stuck WG. A general consideration of metals for buried appliances in surgery. International Abstracts of Surgery 1943;76:297304.

${ }^{2}$ Ferguson AB, Laing PG, Hodge ES. The ionisation of metal implants in living tissues. F Bone foint Surg 1960;42A:77-90.

3 Mears DC. Electron-probe microanalysis of tissue and cells from implant area. F Bone foint Surg 1966;48B:567-76.

4 Samitz MH, Katz SA. Nickel dermatitis hazards from prostheses. $\mathrm{Br} \mathcal{F}$ Dermatol 1975;92:287-90.

${ }^{5}$ Coleman RF, Harrington J, Scales JT. Concentration of wear products in hair, blood, and urine after total hip replacement. $\mathrm{Br} M e d \mathcal{F} 1973$;i : 527-9.

${ }^{6}$ Cronin E, Wilkinson D. Contact dermatitis. In: Rook A, ed. Recent advances in dermatology. No 3. Edinburgh: Churchill Livingstone, 1973:134-92.

7 Benson MKD, Goodwin PG, Brostoff J. Metal sensitivity in patients with joint replacement arthroplasties. $\mathrm{Br}$ Med $\mathcal{F} 1975$;iv:374-5.

${ }^{8}$ Elves MW, Wilson JN, Scales JT, Kemp HBS. Incidence of metal sensitivity in patients with total joint replacements. $B r \operatorname{Med} ₹ 1975$;iv: 376-8.

9 Deutman R, Mulder TJ, Brian R, Nater JP. Metal sensitivity before and after total hip arthroplasty. $\mathcal{F}$ Bone foint Surg 1977;59A :862-5.

10 Elves MW. The development of metal sensitivity in recipients of total joint replacement. $\mathcal{F}$ Bone foint Surg $1977 ; 59 B: 247-8$ 
${ }^{11}$ Christiansen $\mathrm{KJ}$. The correlation between prosthesis failure and metal sensitivity as determined by a new immunological technique. $\mathcal{F}$ Bone foint Surg $1979 ; 61 B: 240$.

12 Mayor MB, Merritt K, Brown SA. Metal allergy and the surgical patient. Am f Surg 1980;139:477-9.

${ }^{13}$ Evans EM, Freeman MAR, Miller AJ, Vernon-Roberts B. Metal sensitivity as a cause of bone necrosis and loosening of the prosthesis in total joint replacement. F Bone foint Surg 1974;56B :626-42.

14 Jones DA, Lucas HK, O'Driscoll M, Price CHG, Wibberley B. Cobalt toxicity after McKee hip arthroplasty. $\mathcal{F}$ Bone Foint Surg 1975;57B : 289-96.

15 Brown GC, Lockshin MD, Salvati EA, Bullough PG. Sensitivity to metal as a possible cause of sterile loosening after cobalt-chromium total hipreplacement arthroplasty. $\mathcal{F}$ Bone foint Surg 1977;59A:164-8.

${ }^{16}$ Foussereau J, Laugier P. Allergic eczemas from metallic foreign bodies Transactions. St Fohn's Hospital Dermatological Society 1966;52:220-5.

17 McKenzie AW, Aitken CVE, Ridsdill-Smith R. Urticaria after insertion of Smith-Petersen Vitallium nail. Br Med F 1967 ;iv :36.

18 Barranco VP, Solomon H. Eczematous dermatitis from nickel. FAMA $1972 ; 220: 1244$.

19 Symeonides PP, Paschaloglou C, Papageorgiou S. An allergic reaction after internal fixation of a fracture using a Vitallium plate. $\mathcal{f}$ Allergy Clin Immunol 1973;51:251-2.

${ }^{20}$ Pegum JS. Nickel allergy. Lancet $1974 ; \mathrm{i}: 674$.

21 Fisher AA. Allergic dermatitis presumably due to metallic foreign bodies containing nickel or cobalt. Cutis 1977;19:285-6, passim.

22 Halpin DS. An unusual reaction in muscle in association with a Vitallium plate: a report of possible metal hypersensitivity. $\mathcal{F}$ Bone foint Surg $1975 ; 57 B$ : $451-3$.

${ }^{23}$ Lyell A, Bain WH. Nickel allergy and valve replacement. Lancet 1974 ;i : 408-9.

\section{Haemoglobin $A_{1}$ and diabetes: a reappraisal}

Diabetic patients were found to have an unusual haemoglobin in their red cells as long ago as $1968 .{ }^{1}$ This haemoglobin (haemoglobin $\mathrm{A}_{1} ; \mathrm{HbA}_{1}$ ) was later shown to reflect the presence of persistent hyperglycaemia ; a raised blood glucose concentration slowly and constantly modifies haemoglobin $\mathrm{A}$ by binding glucose in a stable ketoamine linkage to the $\mathrm{N}$-terminal valine of the haemoglobin $\beta$-chain. ${ }^{2} \mathrm{An}$ appreciable increase in the amount of stable $\mathrm{HbA}_{1}$ in the blood probably takes days or weeks to appear, while its return to normal during routine diabetic control occurs over several weeks. ${ }^{3} \mathrm{HbA}_{1}$ is made up of three fractions named $a, b$, and c. It was the first example of alteration of the composition of a protein after its synthesis by the body, but this is now known to affect other proteins including albumin. Indeed, because of its short half life it has been suspected that glycosylated albumin might provide an indication of short-term diabetic control. ${ }^{4}$ The functional consequences of glycosylation of proteins remain unknown despite much speculation.

Many studies have established a correlation of $\mathrm{HbA}_{1}$ with the blood glucose concentration, especially with blood glucose profiles taken between four and 12 weeks before. ${ }^{5}{ }^{6}$ The great value of measurements of $\mathrm{HbA}_{\mathbf{1}}$ is that they appear to reflect overall blood glucose concentrations independently of day-today fluctuations. Because $\mathrm{HbA}_{1}$ reflects blood glucose control retrospectively it provides unique information in circumstances such as the evaluation of the first trimester of pregnancy. Nevertheless, while the concept of glycosylated haemoglobin as an indicator of long-term diabetic control has gained wide acceptance, the problems encountered with its measurement have led to some doubts about its value in routine clinical practice.

The amount of $\mathrm{HbA}_{1}$ in the blood depends to some extent on red-cell turnover, since its formation takes place during the whole life of the red cell. Values are reduced if the rate of redcell turnover is increased. Low values have been reported in haemolytic anaemias ${ }^{7}$ and haemoglobinopathies in particular, and during venesection in patients with haemochromatosis. ${ }^{8}$ Large amounts of $\mathrm{HbA}_{1}$ are found in patients with irondeficiency anaemia, ${ }^{9}$ and in uraemic patients both high ${ }^{10}$ and low ${ }^{11}$ values have been recorded. Alterations also occur in lipaemia, and there are some changes, too, with age. ${ }^{12}$

Many difficulties have been experienced with laboratory methods for determination of $\mathrm{HbA}_{1}$. Different methods give different results, no standards are yet available, and in methods based on column chromatography the temperature of the column is of critical importance. Prolonged storage of specimens, even when refrigerated, also leads to changes of $\mathrm{HbA}_{1}$. It is probably stable for about three days when whole blood is stored at $4^{\circ} \mathrm{C},{ }^{12}$ but we have little reliable information about any changes when blood samples are left standing at room temperature.

An unstable component of $\mathrm{HbA}_{1}$ is now known to exist, perhaps representing the Schiff base, which is formed as the initial step in the formation of glycosylated haemoglobin. Short-term hyperglycaemia can therefore cause relatively rapid changes in $\mathrm{HbA}_{1}$. Experiments in vivo and in vitro have shown that the amount of $\mathrm{HbA}_{1}$ can increase within a few hours in the presence of severe hyperglycaemia; when control is reestablished it decreases again within six hours if the artificial pancreas is used, ${ }^{12}{ }^{13}$ but the same response takes a few days if routine treatment with insulin is given. ${ }^{12}$ Increases also occur within a few days if sulphonylureas are withdrawn $\mathrm{n}^{14}$ or when the insulin dose is drastically reduced. ${ }^{15}$ Similar reversible changes occur if red cells are incubated with glucose. ${ }^{12}$ The errors resulting from the presence of unstable $\mathrm{HbA}_{1}$ may be large: the normal range of $\mathrm{HbA}_{1}$ is between $4 \%$ and $8 \%$ of the total $\mathrm{HbA}$, but this fraction may be increased in vitro by a further $3 \%$ or more owing to the unstable component. In routine outpatient studies, however, the unstable fraction rarely accounts for more than $1.5 \% .^{12} 16$ Clearly, if measurement of $\mathrm{HbA}_{1}$ is to be of value in the assessment of long-term diabetic control the unstable component must be removed before analysis. Svendsen $e t a l,^{12}$ who reviewed this subject thoroughly, recommend incubation of red cells in a low glucose medium at $37^{\circ} \mathrm{C}$ for several hours to eliminate the unstable fraction; or dialysis methods can be used.

These observations on unstable $\mathrm{HbA}_{1}$ inevitably cast doubt on the reliability of many of the earlier published reports. In future, close attention must be given to storage of samples, elimination of the unstable fraction, and quality control of laboratory methods, and each centre needs to perform its own control measurements. Then measurement of $\mathrm{HbA}_{1}$ should still provide the unique retrospective assessment of long-term diabetic control which its advocates have claimed. In the clinic a single value of $\mathrm{HbA}_{1}$ provides limited information, though a series of values over months or years might prove very useful. Despite the present uncertainties, a normal amount of $\mathrm{HbA}_{1}$ is likely to indicate very good blood glucose control. It is disappointing that so few insulin-dependent diabetics actually achieve this, ${ }^{17}$ and that even then some do so only at the expense of nocturnal hypoglycaemia. ${ }^{18}$

1 Rahbar S. An abnormal hemoglobin in red cells of diabetics. Clin Chim Acta 1968;22:297-8.

${ }^{2}$ Bunn HF, Shapiro R, McManus M, et al. Structural heterogeneity of human hemoglobin A due to nonenzymatic glycosylation. $\mathcal{F}$ Biol Chem $1979 ; 254: 3892-8$.

${ }^{3}$ Ditzel J, Kjaergaard J-J. Haemoglobin $A_{1}$ concentrations after initial insulin treatment for newly discovered diabetes. $\mathrm{Br} M e d \mathcal{F} 1978$;i:741-2.

4 Dolhofer R, Wieland OH. Increased glycosylation of serum albumin in diabetes mellitus. Diabetes $1980 ; 29: 417-22$. 